\title{
Representações sociais de universitários de psicologia acerca da maconha
}

\author{
Psychology students' social representations \\ about marijuana
}

\author{
Aline Arruda da FONSECA ${ }^{1,4}$ \\ Regina Lígia Wanderley de AZEVEDO ${ }^{1,4}$ \\ Ludgleydson Fernandes de ARAÚJO ${ }^{2,4}$ \\ Suenny Fonsêca de OLIVEIRA ${ }^{2}$ \\ Maria da Penha de Lima COUTINHO ${ }^{3,4}$
}

\begin{abstract}
Resumo
O uso abusivo de substâncias psicoativas lícitas e ilícitas ganhou proporções tão alarmantes que, na atualidade, é um desafio da saúde pública. Salienta-se que a maconha é a droga ilícita mais utilizada no Brasil. Esta pesquisa objetivou investigar as representações sociais de estudantes de Psicologia acerca da maconha. Participaram 200 universitários de ambos os sexos (76,2\% feminino), com idades entre 18 e 26 anos. Foi utilizado o Teste de Associação Livre de Palavras, tendo como estímulo indutor a palavra maconha. Os dados foram processados pelo software tri-deux-mots (versão 6.1) por meio da análise fatorial de correspondência. Os resultados apontaram diferenças de gênero nas formas de representarem a maconha. Os universitários objetivaram a maconha nas questões voltadas para a busca do prazer/hedonismo e as universitárias nos aspectos psicossociais. Os estudantes mais jovens apresentaram uma visão negativa da erva e os mais velhos deram ênfase ao preconceito sofrido pelos usuários.
\end{abstract}

Unitermos: estudantes, psicologia; maconha; representações sociais.

\begin{abstract}
The abusive use of allowed and illicit psychoactive substances has got alarming dimensions as it, in the present time, is a challenge for the public health. It is known that marijuana is the most used illicit drug in Brazilian reality. This research had as objective to investigate Social Representations of Psychology students concerning marijuana. Two hundred college students participated; from both sex (feminine 76.2\%), whose ages were around 18 to 26 years. The Words Free Association Test was used, having as stimulation-inductor the word marijuana. The data had been processed by software tri-deux-mots (version 6.1) through the factorial analysis of correspondence. The results had pointed differences of sort in the forms to represent marijuana. The college male students objectified marijuana to questions directed towards pleasure/ hedonism, while the female ones to psychosocial aspects. Theyounger students presented a negative vision about the grass, and the oldest ones gave emphasis to the preconception suffered by the users.
\end{abstract}

Uniterms: students, psychology; marijuana; social representations.

$\boldsymbol{\nabla \nabla v \nabla}$

1 Universidade Federal da Paraíba, Centro de Ciências Humanas, Letras e Artes, Departamento de Psicologia. Cidade Universitária, s/n., Campus I, Castelo Branco II, 58051-900, João Pessoa, PB, Brasil. Correspondência para/Correspondence to: A.A. FONSECA. E-mail: <alineufpb@hotmail.com>.

2 Universidade Federal do Piauí, Departamento de Psicologia. Parnaíba, PI, Brasil.

3 Universidade Federal da Paraíba, Programa de Pós-Graduação em Psicologia Social. João Pessoa, PB, Brasil.

- Universidade Federal da Paraíba, Núcleo de Pesquisa: Aspectos Psicossociais de Prevenção e Saúde Coletiva. João Pessoa, PB, Brasil. 
A utilização de drogas faz parte da história da humanidade, sendo difícil separar o seu uso do contexto sociocultural e histórico vigente. Nesse sentido, achados antropológicos podem revelar como eram e são utilizadas as variadas substâncias psicoativas inseridas nos mais diversos contextos. É possível verificar, ainda, finalidades terapêuticas, religiosas ou recreativas, que variam de sociedade para sociedade quanto ao tipo de rituais e significado do seu consumo (Gontiès \& Araújo, 2003).

A maconha, cujo nome cientifico é Cannabis sativa - do latim Cannabis, que significa cânhamo, denominando o gênero da família da planta; e sativa, que se refere à cultura plantada ou semeada, indicando a espécie e a natureza do desenvolvimento da planta (Coutinho, Araújo \& Gontiès, 2004; Gontiès \& Araújo, 2003), - é considerada atualmente a droga ilícita mais utilizada pela maioria dos jovens no Brasil (Soldera, Dalgalarrondo \& Correa Filho, 2004), assim como mundialmente.

O seu uso comumente é intermitente e limitado: os jovens param por volta dos seus 20 anos, e poucos entram num consumo diário por anos seguidos. No que tange à dependência, a maconha está entre as substâncias psicoativas mais comuns; um em dez daqueles que usaram maconha na vida se tornaram dependentes em algum momento, considerando-se um período de quatro a cinco anos de consumo pesado (Jungerman, Laranjeira \& Bressan, 2005).

Os efeitos e os riscos provenientes do uso de qualquer tipo de droga estão associados a uma série de fatores que devem ser observados pela sociedade como um todo, e principalmente pelos programas de prevenção e reabilitação de dependentes químicos. 0 tipo de substância; a qualidade da droga; a forma de ingestão; a quantidade utilizada; as características físicas e psicológicas do usuário; o período da vida; a expectativa dos efeitos e as circunstâncias são os aspectos mais importantes a serem considerados (Araújo, 2005; MaCrae \&Simões, 2000).

De acordo com a Agência de Notícias dos Direitos da Infância - ANDI (2005), quando se fala de substâncias psicoativas consideradas ilícitas, as discussões se voltam com mais freqüência a casos extremos, tais como a dependência, suicídio, acidentes e violência. Essa agência ainda aponta para a ausência 442 de intervenções para amenizar o uso abusivo de drogas com enfoque na prevenção em saúde, contrapondo-se à repressão que se pauta nos estereótipos negativos associados comumente à violência e à marginalização.

Assim, o uso indevido de drogas é alvo de debates e questionamentos nos diversos segmentos da sociedade e tem sido considerado um problema de saúde pública que afeta, sobretudo, jovens e adolescentes, pela capacidade de induzir a prazeres e novas sensações. Esse fenômeno tem suscitado preocupação, pois além de provocar uma pluralidade de danos aos usuários, envolve a sociedade de maneira geral (Bastos, 2003; Bucher, 1998).

O uso abusivo da maconha entre adolescentes dos países desenvolvidos vem aumentando significativamente nas últimas décadas. Uma das possíveis explicações para esse fato é a percepção de que a maconha é uma "droga leve", sem muitas conseqüências para a saúde do indivíduo, em contraste com outras drogas ilícitas (Weiser, Soares-Weiser \& Davidson, 2003).

Os efeitos físico-orgânicos da maconha no organismo dos usuários são: hiperestesia sensorial com perturbação têmporo-espacial acompanhada de euforia ou angústia; hiperemia conjuntiva; diminuição da pressão ocular; sensação de boca seca; taquicardia; aumento do apetite devido à diminuição da glicose no sangue; falta de coordenação motora, semelhante aos efeitos da embriaguez, com diminuição dos reflexos; atividade anticonvulsivante e diminuição da produção de hormônios sexuais (Carlini, Galduróz \& Noto, 2004; Costa \& Gontiès, 1997; Gontiès \& Araújo, 2003).

Uma pesquisa realizada por Pinton, Boskovitz e Cabrera (2002), com estudantes do curso de Medicina da Faculdade de Medicina de São José do Rio Preto, SP, cujo objetivo foi avaliar o consumo de drogas entre os estudantes, teve como resultado o uso da maconha por 25\% dos alunos entrevistados. No estudo desses autores, um dado foi de grande relevância: $80 \%$ dos estudantes enfatizaram a necessidade de a escola aconselhar as pessoas que estão na categoria de usuário ocasional, e 25\% alegaram que a instituição deve afastar o usuário dependente. Esse dado demonstra o preconceito e estigmatização enfrentada pelo dependente de substâncias psicoativas, tendo como grave conseqüência a exclusão social.

Como base para este estudo, recorreu-se à teoria das representações sociais (RS) proposta por Moscovici 
(1981), pela sua importância na análise de aspectos psicossocioculturais que permeiam o processo saúde/doença e as práticas sociais relativas ao mesmo, bem como pelos atos de comunicação social e fenômenos coletivos que contribuem para a formação de condutas e de normas que regem o pensamento social.

O estudo das representações sociais vem sendo cada vez mais valorizado em vários campos de estudo, como educação, sociologia, antropologia, saúde, dentre outras áreas científicas, tornando-se um campo ampliado de pesquisa e englobando uma variedade de assuntos, haja vista a representação, como afirma Jodelet (2001, p.16), "ser uma atividade inerente à condição humana, possibilitando aos sujeitos compreender e dominar física e intelectualmente o mundo que os rodeia, fator presente em qualquer contexto biopsicosocial".

No campo dessa teoria, estudos relacionados às questões da prática de saúde são de suma importância, pois assumem toda sua significação, possibilitando a apreensão de processos e mecanismos pelos quais o sentido do objeto de estudo é construído pelos sujeitos concretos - neste caso, os estudantes de Psicologia - em suas relações cotidianas. Assim, no caso do uso da maconha, podem estar imbricados aspectos pessoais, como a necessidade de afirmação do indivíduo, o afeto, demandas, busca de prazer em conjunção com normas, valores, informações e outros fatores de diferentes ordens.

Dito de outra forma, considera-se a RS como o sentido atribuído a um dado objeto pelo sujeito do senso comum, a partir das informações adquiridas na prática e nas suas relações cotidianas (Marková, 2006). Sua construção acontece, assim, a partir da elaboração de informações de diferentes ordens, que são continuamente transformadas, recriadas, articulando instâncias, níveis e dimensões (Madeira, 2001).

Por meio dos meios de comunicação como um todo, difundem-se informações sobre essa substância psicoativa, podendo, assim, o indivíduo escolher evitá-la ou consumi-la. Nesse enfoque, a maconha tornou-se objeto de preocupação no que diz respeito não apenas aos jovens e adultos, mas também aos adolescentes, que estão vivenciando uma fase de profundas mudanças.
Essa população conhece a maconha por meio das conversas cotidianas, conselhos, e contato com a mídia preventiva. Essa forma de conhecimento não especializado, do senso comum, é o que caracteriza o fenômeno das representações sociais da maconha, fator intimamente ligado à vida social. Nesse contexto, as representações que os adolescentes, os jovens e os adultos constroem acerca da maconha são imersas nesse movimento de mensagens, organizado cognitivamente conforme as diferentes modalidades de comunicação. Moscovici (1981) classifica e analisa três sistemas indutores dessas representações: a difusão, a propagação e a propaganda (Jodelet, 2001; Nóbrega, 2003).

Assim sendo, investigar as representações sociais dos estudantes de Psicologia acerca da maconha é resgatar um conhecimento elaborado e compartilhado de maneira coletiva, permitindo evidenciar os diferentes conteúdos e a estrutura interna desse conhecimento. Tais representações sociais podem servir de princípios para embasar a prática profissional desses futuros psicólogos diante da prevenção do uso indevido de psicotrópicos.

É importante considerar, também, que o conhecimento sobre os riscos para a saúde é alcançado de duas maneiras: pela experiência individual (e direta) ou pela experiência coletiva (mediada pelos grupos sociais). No caso da maconha, tanto o primeiro quanto o segundo modo são comuns. Contudo vale salientar que Moscovici (1981) não se refere à representação como uma reprodução estática, mas compreende que o ato de representar é responsável por inúmeras transformações entre o que é externo e o que a ele é devolvido. Entende-se, assim, que, ao representar a maconha, o estudante de Psicologia não simplesmente a produz, mas a reconstrói, levando essa modificação como marca de sua passagem pelo psiquismo individual e coletivo (Gontiès, Maciel \& Moreira, 2001).

Objetivou-se, portanto, conhecer empiricamente as RS da maconha em uma amostra de estudantes universitários de Psicologia, tendo em vista que esses futuros profissionais de saúde poderão promover ações preventivas a partir de estratégias de caráter educativo. Conhecer tais representações facilita a compreensão dos aspectos de interdependência dos sujeitos em seu grupo e sua relação com o ambiente psicossocial. 


\section{Método}

Trata-se de um estudo descritivo exploratório, de caráter qualitativo e quantitativo, que foi desenvolvido no Centro de Ciências Humanas, Letras e Artes da Universidade Federal de Paraíba (UFPB). Foram investigados os conhecimentos construídos socialmente e difundidos entre os universitários de Psicologia dessa instituição de ensino superior.

\section{Participantes}

A amostra pesquisada foi composta por 200 universitários de Psicologia, de ambos os sexos - 48 do sexo masculino (24\%) e 152 do sexo feminino (76\%) -, na faixa etária entre 18 e 26 anos (média=21, desvio-padrão=2,29), em situação acadêmica regular, cursando do $1^{\circ}$ ao $10^{\circ}$ período. Essa amostra foi do tipo não probabilística, intencional e acidental. É válido mencionar que não foram consideradas nesta pesquisa as diferenças de períodos cursados entre os universitários.

\section{Instrumentos}

O instrumento utilizado para a coleta dos dados foi o Teste de Associação Livre de Palavras: um instrumento bastante difundido na Psicologia Clínica. No entanto o seu emprego no âmbito da Psicologia Social, na área das representações sociais, deu-se a partir de adaptação feita em pesquisas realizadas por Di Giacomo (1981), nas quais se visava verificar os conteúdos latentes das representações sociais por meio do material evocado em relação a um estímulo indutor (Nóbrega \& Coutinho, 2003).

Faz-se necessário salientar que esse instrumento, na atualidade, tem sido bastante utilizado na abordagem multimétodos pelos pesquisadores das RS (Coutinho, 2005), uma vez que permite acesso aos conteúdos latentes da representação que não são apreendidos por outros instrumentos, como, por exemplo, a entrevista, devido às normas, aos valores e à desejabilidade social cristalizados nos conteúdos elaborados nas falas dos participantes (Flick, 2004).

De acordo com Nóbrega e Coutinho (2003), essa técnica projetiva possibilita acesso aos conteúdos

444 latentes, sem que ocorra a filtragem da censura a sua evocação. Também é um instrumento que se apóia sobre um repertório conceitual, permitindo, com isso, a unificação dos universos semânticos e a saliência de universos de palavras comuns diante dos estímulos indutores e participantes da pesquisa.

\section{Procedimentos}

Inicialmente, foi mantido contato com a coordenação do curso de Psicologia da UFPB com a finalidade de obter a autorização para desenvolvimento do estudo. Os participantes responderam ao instrumento individualmente e de forma coletiva, em salas de aulas previamente definidas, com anuência dos professores. Foi assegurado o anonimato dos respondentes, e foi explicado que se tratava de participação voluntária. Mesmo sendo um instrumento auto-administrável, foram repetidas em voz alta todas as instruções previamente descritas para o procedimento de respostas, as quais se encontram impressas no instrumento. Posto isso, foi mencionado um exemplo com intuito de familiarizar o participante com a funcionalidade do instrumento. Em seguida, foi apresentado o estímulo indutor com uma questão: "o que the vem à mente quando digo a palavra Maconha?" É válido mencionar que os universitários, em sua maioria, destacaram expressões que, posteriormente, foram transformadas em palavras associadas. Não foi identificada nenhuma recusa em participar da presente pesquisa, e o tempo de sua aplicação foi de aproximadamente 15 minutos. Por fim, após checados os instrumentos, agradeceu-se a colaboração e foi disponibilizado um correio eletrônico para devolução dos principais resultados da pesquisa.

\section{Análise}

Os dados obtidos a partir do Teste de Associação Livre de Palavras foram processados e analisados pelo software tri-deux-mots (Cibois, 1998), versão 6.1, que permite a visualização gráfica tanto das variáveis fixas (sexo, período e idade), bem como das variáveis de opinião, que foram enunciadas pelos participantes diante do estímulo indutor maconha.

As variáveis fixas foram codificadas seguindo o plano de análise a seguir:

- Variável sexo: masculino, feminino; - variável período: $1^{\circ}$ - 30 período; $4^{\circ}$ - 70 período; $8^{\circ}$ - $10^{\circ}$ período; 
- variável faixa etária: 1) 18-20 anos; 2) 21-23 anos; 3) 24-26 anos.

\section{As etapas operacionais foram:}

Primeiro, preparou-se um dicionário correspondente ao estímulo indutor com as respostas evocadas pelos participantes.

Em seguida, as enunciações foram selecionadas, por ordem alfabética, para a realização da análise de conteúdo. Realizou-se a organização das palavras pelas suas respectivas freqüências, que indicaram maior relevância estatística, agrupando-as com as de menor freqüência, levando-se em consideração as sinonímias e similitudes semânticas. Por exemplo, os universitários mencionaram "droga", "bagulho" e "psicotrópico", que foram agrupadas em uma categoria única - droga - para contribuir com a compreensão da representação da maconha.

Após essa etapa inicial, organizou-se o banco de dados, sendo perfiladas as variáveis fixas (nesta investigação foram: sexo, período e faixa etária) e, posteriormente, as palavras associadas ao estímulo indutor (maconha). No que concerne à análise dos dados, utilizou-se o software tri-deux-mots idealizado por Cibois (1998), na França, por meio da Análise Fatorial de Correspondência (AFC), por permitir uma visualização das correlações entre os elementos do campo representacional da maconha, apreendidos entre os participantes desta pesquisa.

Esse software é, com freqüência, utilizado para tratamento de dados qualiquantitativos de questões abertas, fechadas e/ou associação livre de palavras. Nesse sentido, o pacote estatístico tem apresentado fidedignidade e valor preditivo consideráveis nas pesquisas que possuem embasamento teórico-metodológico das representações sociais.

De acordo com Coutinho (2005), a AFC é pertinente para processar e analisar os dados operacionalizados pela técnica utilizada neste estudo, denominada Teste de Associação Livre de Palavras, posto que essa análise coloca em evidência as variáveis fixas (em colunas) e as variáveis de opinião (em linhas) que se fazem representadas no plano fatorial. A partir da AFC, pode-se verificar os vínculos de atração entre as respostas dos indivíduos que são simultaneamente apresentadas de maneira oposta às associações de outros grupos.

\section{Resultados}

A técnica de associação livre de palavras fez emergir 39 palavras principais com similaridade semântica. Palavras como "alegria", "festa", "risos" foram agrupadas na mesma terminologia "descontração". Os resultados coletados e apresentados no Figura 1 oferecem uma leitura que representa variações semânticas na organização do campo espacial, revelando aproximações e oposições das modalidades, conforme pode ser observado no plano fatorial por meio dos dois fatores nele contemplados (F1 e F2).

Assim na Figura 1 pode ser verificada, mediante a evocação da palavra maconha, a oposição de pensamentos entre os estudantes masculinos e femininos do curso de Psicologia da UFPB e aqueles com idades entre 18 e 26 anos, independentemente do gênero. No total, os dois fatores têm poder explicativo de 73,3\%.

O F1, na linha horizontal, em negrito, concerne ao fator majoritário de maior poder explicativo, com $43,1 \%$ da variância total das respostas. O F2, na linha vertical, em itálico, possui 30,2\% da variância total das respostas.

Na parte horizontal, em negrito, pode-se observar as representações sociais dos estudantes universitários do curso de Psicologia acerca da maconha. Do lado esquerdo da Figura 1, em negrito, têm-se os estímulos

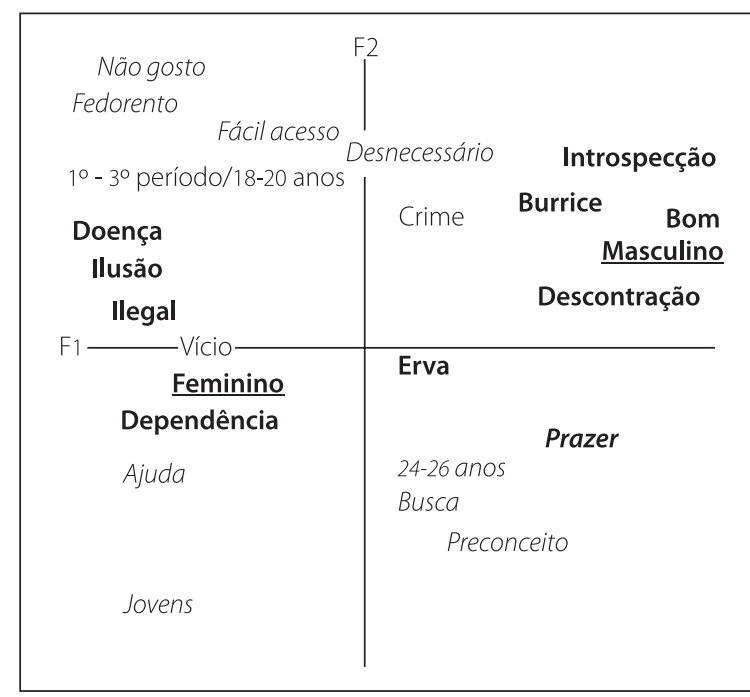

Figura 1. Representações sociais da maconha em universitários de Psicologia. 
emergidos pelas estudantes do sexo feminino, as quais ancoraram a maconha à doença, à ilegalidade, à ilusão, ao vício e à dependência. No lado direito do gráfico, encontram-se as variáveis de opinião dos estudantes do sexo masculino, que trouxeram representações semânticas da maconha como uma erva que estimula algo bom e que tem como conseqüência a introspecção, a descontração e o prazer.

Em oposição ao F1, no F2 do eixo vertical, em itálico, na parte superior do gráfico, têm-se as representações dos estudantes de ambos os sexos com idades de 18 a 20 anos, que trouxeram como contribuições semânticas da maconha: mau cheiro, que não gostam, de fácil acesso, mas que é desnecessário. Além dessa representação, essa faixa etária enfatizou ainda o crime como uma forma de conseqüência negativa que acompanha o uso da erva.

Na parte inferior da Figura 1, também em itálico, observa-se o campo semântico dos estudantes mais velhos (24 a 26 anos) e de ambos os sexos, que, provavelmente, encontravam-se no final do curso. Esses adultos jovens representaram a maconha como a busca de algo por parte dos jovens, e que é uma questão que necessita de muita ajuda, pois além dos danos fisicos e psicológicos causados pela erva, existe ainda a questão do preconceito.

\section{Discussão}

Pelos resultados apresentados, pode-se acrescentar alguns aspectos que devem ser considerados, pois a forma como os estudantes universitários representam as drogas (lícitas e ilícitas) se apresenta como um campo de estudo bastante favorável para o estabelecimento de políticas preventivas em saúde.

Considerando-se os aspectos de gênero, verificaram-se divergências na forma como os estudantes universitários representam a maconha. A mulher enfatiza aspectos sociomorais quando retrata a ilegalidade, a ilusão, a doença e a dependência; e o homem, a busca de sensações proporcionadas pelo uso da maconha, traduzido-as por descontração e por prazer.

Assim, percebe-se que as universitárias objetivaram suas representações nas concepções psicossociais, resgatando a seriedade e os problemas que essa substância psicoativa pode causar ao seu usuário, aos seus familares e à sociedade. A ilegalidade do uso emergiu como forma de demonstrar que, mesmo sendo proibida, sua difusão é evidente na sociedade, transformando-se num problema de ordem social, de forma que, como afirmam Gontiès et al. (2001), o consumo de drogas tem se transformado, nas últimas décadas, em um tema de grande relevância e interesse na sociedade.

Os aspectos biológicos e psicológicos também são retratados no campo semântico dessas jovens quando enfatizam a ilusão, a dependência e a doença causadas pelo uso da maconha. A dependência, aqui como causadora de doença, está relacionada ao uso intermitente da droga, que provoca problemas psicossociais, físico-orgânicos e socioafetivos.

O tempo de uso da droga deve ser considerado de grande relevância nos estudos dos danos nas áreas biológica e psicológica, já que há uma pequena evidência de que usuários de longo prazo, que iniciaram um uso regular no início da adolescência, apresentam atrofia cerebral assim como redução na substância cinzenta (Crippa, Lacerda \& Amaro, 2005).

De forma consonante às RS das universitárias de Psicologia, a literatura especializada destaca que o uso regular ou pesado da maconha está associado a maiores taxas de uma série de outras condições, como problemas de ajustamento psicossocial, o uso de outras substâncias psicoativas ilícitas, criminalidade, depressão e condutas suicidas (Fergusson, Horwood \& Swain-Campbell, 2002).

Estudos realizados com neuroimagem funcional relatam aumento na atividade neural em regiões que podem estar relacionadas com intoxicação por cannabis, alteração do humor (lobos frontais mesial e orbital) e redução na atividade de regiões relacionadas com funções cognitivas prejudicadas durante a intoxicação aguda (Crippa et al., 2005).

Em contrapartida, verificou-se que os universitários da presente pesquisa representaram a maconha numa visão diferenciada da observada pelas universitárias. Esses jovens resgatam o lado do prazer obtido no uso da maconha, levando a momentos de brincadeira e descontração. Esse dado pode estar interligado à difusão por meio dos grupos de pertença, bem como 
da mídia, em especial a Internet, de que a maconha ocasiona esse efeito relaxante e prazeroso.

Um fórum sobre maconha, saúde, doença e liberdade foi realizado na Internet por Lefèvre e Siomioni (1999), no qual foram debatidas questões acerca dos benefícios, malefícios e sensações que o uso da maconha pode causar. Um dos dados encontrados nesse estudo foi de jovens que relataram como idéia central que a maconha não faz mal, não prejudica o viver cotidiano e ainda promove o bem-estar e o relaxamento.

Esse é um dado igualmente referenciado nos estudos de Bastos (2003), que menciona que o consumo da maconha é encarado como uma busca desenfreada de prazer/hedonismo. Tal fato se deve provavelmente à fácil acessibilidade e disponibilidade que ocasiona um aumento significativo no uso indevido dessa substância psicoativa (Gontiès \& Araújo, 2003).

Considerando-se os resultados referentes à faixa etária, observou-se que os estudantes mais jovens (18 a 20 anos) traduzem a maconha de maneira negativa, demonstrando fatores de repulsa quando falam do mau cheiro e do mau gosto. É importante ressaltar que esses jovens, igualmente àqueles do sexo feminino, referem-se a problemas sociais que a maconha pode causar, pois objetivam essa substância psicoativa a uma visão sociomoral.

Nas representações dos jovens com idades entre 24 e 26 anos, verificou-se uma abordagem psicossocial amparada no preconceito. Para esses jovens, o uso da maconha é gerador de preconceito e discriminação, sendo verificada a necessidade de apoio e ajuda para com seus usuários. Esse dado é refletido na literatura por MacRae e Simões (2000), quando afirmam que na realidade brasileira os usuários de maconha estão em constante situação de estigmatização, assédio social e violência. Freqüentemente observam-se ações repressoras para com essa população, sem levar em consideração os aspectos biopsicossociais e culturais que estão intrinsecamente relacionados ao uso das drogas (Carlini, 2002; Gontiès \& Araújo, 2003).

Nesse sentido, esse fato reflete a necessidade de uma integração de ações preventivas de controle e de tratamento, de forma a atuar no pólo de demanda com trabalho de prevenção socioeducativa (Coutinho et al., 2004).
A partir desses dados, verifica-se que o consumo da maconha comumente apresenta-se em três vertentes, que são enfatizadas por Uchôa (2003): aqueles que adotam posturas radicalmente contra o seu uso, associando-o à marginalização e à violência, que reflete na nossa sociedade os estereótipos negativos e preconceitos; outra posição diz respeito àqueles que defendem o uso da cannabis com a retórica de que se trata de uma erva natural e que não traz danos à saúde, como também não traz nenhum ônus à vida sociocultural do usuário. Verificou-se também a presença dos que não adotam ou preferem não adotar nenhuma posição acerca do uso da maconha - neste estudo, os jovens com faixa etária entre 21 e 23 anos; o que não emergiu no gráfico por não ter tido nenhuma representação significativa.

\section{Considerações Finais}

O presente estudo versou sobre as representações sociais que os estudantes de Psicologia da UFPB têm acerca da droga ilícita mais utilizada na atualidade: a maconha. Os dados apreendidos possibilitaram representações consensuais e particulares de acordo com o gênero e a faixa etária em que se encontravam esses jovens.

Nesse sentido, é de suma importância apreender as representações acerca das drogas por parte dos estudantes do curso de Psicologia, uma vez que elas serão determinantes de suas práticas e, segundo Andrade (2003), são eles que vão coordenar e gerenciar num futuro próximo essa problemática que afeta tanto o indivíduo como sua família.

Verificou-se, ainda, que o consumo de drogas acontece nas diversas esferas da sociedade. É algo complexo, que envolve uma série de fatores políticos, econômicos, culturais e sociais, que devem ser considerados nas investigações científicas para seu melhor entendimento. São necessárias, então, pesquisas que contemplem as representações de futuros profissionais das mais diversas áreas, quanto ao uso da maconha, uma vez que esse conhecimento poderá contribuir nas suas práticas, no âmbito da intervenção e promoção da saúde.

Nesse cenário, insere-se o papel imprescindível a ser desempenhado conjuntamente pela tríade univer- 
sidade, família e sociedade, na formulação/implementação de ações positivas que amenizem o uso indevido das drogas no contexto universitário. Faz-se necessário o desenvolvimento de atividades culturais, religiosas e desportivas, bem como a instalação de comitês antidrogas nos estabelecimentos de ensino, com o intuito de fomentar fóruns de discussão permanente acerca da prevenção primária das drogas lícitas e ilícitas.

Diante de tal complexidade, uma compreensão simplista e reducionista, alimentada por despreparo e desconhecimentos científicos contextualizados, é capaz de tornar a atuação desses futuros psicólogos ineficiente perante a questão das substâncias psicoativas. Daí a importância de uma formação acadêmica/profissional que contemple a atuação da psicologia quanto ao uso indevido das drogas como uma questão biopsicossocial, cultural e antropológica.

A presente pesquisa, apesar de contribuir de forma parcimoniosa para a elucidação das RS da maconha entre futuros psicólogos, apresenta algumas limitações em relação aos participantes, tendo em vista que não houve um controle acerca dos períodos cursados de maneira estratificada, nem a investigação de universitários de outros cursos - como, por exemplo, Direito e Medicina - que poderão lidar em sua prática profissional com essa temática.

Por fim, cabe ao contexto universitário a sua participação como locus onde possam ser desenvolvidas ações curriculares e extracurriculares que priorizem a formação do futuro profissional para uma cidadania ativa e digna, com ênfase nos fatores de proteção e diminuindo os fatores de risco, de modo que esses universitários possam vivenciar essa fase do desenvolvimento humano sem a necessidade do uso indevido de drogas.

\section{Referências}

Ministério da Saúde. (2005). Mídia \& drogas: o perfil do uso e do usuário na imprensa brasileira. Coordenação de Veet Vivarta. Brasília: Agência de Notícias dos Direitos da Infância.

Andrade, A. G. (2003). O uso de drogas nas universidades. Revistade Cultura-IMAE, 4 (9), 30-39.

Araújo, L. F. (2005). As drogas agindo no organismo humano. 448 Jornal Mundo Jovem, 357, 14.
Bastos, M. T. (2003). Combate ao narcotráfico. Revista de Cultura-IMAE, 4 (9), 6-11.

Bucher, R. (1998). Drogas e drogadição no Brasil. Porto Alegre: Artes Médicas.

Carlini, E. A. (2002). Legalizar drogas não, descriminalizar sim. Ciência Hoje, 181 (4), 40-45.

Carlini, E., Galduróz, J. C. F., \& Noto, A. R. (2004). V levantamento nacional sobre o uso de drogas psicotrópicas entre estudantes do ensino fundamental e médio da rede pública de ensino nas 27 capitais brasileiras. São Paulo: Unifesp.

Cibois, P. (1998). L'analyse factorielle. Paris: PUF. Collecion "Que sais-je?".

Costa, M. R. S., \& Gontiès, B. (1997) Maconha: aspectos farmacológicos, históricos e antropológicos. Revista Unipê, 1 ( 2), 13-24.

Coutinho, M. P. L., Araújo, L. F., \& Gontiès, B. (2004). Uso da maconha e suas representações sociais: estudo comparativo entre universitários. Psicologia em Estudo, 9 (3), 469-477.

Coutinho, M. P. L.(2005). Depressão infantil e representação social. João Pessoa: Universitária.

Crippa, J. A., Lacerda, A. L. T., \& Amaro, E. (2005). Efeitos cerebrais da maconha: resultados dos estudos de neuroimagem. Revista Brasileira de Psiquiatria, 27 (1), 70-78

Di Giacomo, J. P. (1981) Aspects méthodologiques de l'analyse des répresentations sociales. Cahiers de Psychologie Cognitive, 1 (1), 397-422.

Fergusson D. M., Horwood, L. J., \& Swain-Campbell, N. (2002) Cannabis use and psychosocial adjustment in adolescence and young adulthood. Addiction, 97 (9),1 123-35.

Flick, U. (2004). Uma introdução à pesquisa qualitativa. Porto Alegre: Bookman.

Gontiès B., \& Araújo, L. F. (2003). Os Aspectos legais da maconha no contexto universitário: um estudo das representações sociais. In M. P. L. Coutinho, A. S. Lima, F. B. Oliveira \&M. L. Fortunato (Orgs.), Representações sociais: abordagem interdisciplinar (pp.293-311). João Pessoa: Universitária.

Gontiès B., \& Araújo, L. F. (2003). Maconha: uma perspectiva histórica, farmacológica e antropológica. Mneme-Revista de Humanidades, 4 (7), 01-20.

Gontiès, B., Maciel, S. C., \& Moreira, A. S. P. (2001). Representação social sobre drogas e práticas profissionais. In A. S. P. Moreira (Org.), Representações sociais - teoria e prática (pp.295-317). João Pessoa: Universitária.

Jodelet, D. (2001). Representações sociais. Rio de Janeiro: UERJ.

Jungerman, F. S., Laranjeira, R., \& Bressan, R. A. (2005). Maconha: qual a amplitude dos seus prejuízos? Revista Brasileira de Psiquiatria, 27 (1), 5-6.

Lefevre, F., \& Siomioni, A. M. C. (1999). Maconha, saúde, doença e liberdade: análise de um fórum na internet. Cadernos de Saúde Pública, 15 (2), 161-167. 
MaCrae E., \& Simões, J. A. (2000). Rodas de fumo: o uso da maconha entre camadas médias urbanas. Salvador: UFBA.

Madeira, M. (2001). Representações sociais e educação: importância teórico-metodológica de uma relação. In A. S. P. Moreira. Representações sociais: teoria e prática (pp.123). João Pessoa: Universitária.

Marková, I. (2006). Dialogicidade e representações sociais: as dinâmicas da mente. Petróplois: Vozes.

Moscovici, S. (1981). Psycologie sociale. Paris: PUF.

Moscovici, S. (2003). Representações sociais: investigações em psicologia social. Petrópolis: Vozes.

Nóbrega, S. M. (2003). Sobre a teoria das representações sociais. In A. S. P. Moreira, \& J. C. Jesuíno. Representações sociais: teoria e prática (pp.55). João Pessoa: Universitária.

Nóbrega, S. M., \& Coutinho, M. P. L. (2003). O teste de associação livre de palavras. In M. P. L. Coutinho \& A. S. Lima, F. B. Oliveira \& M. L. Fortunato (Orgs.), Repre- sentações sociais: abordagem interdisciplinar (pp. 67-77), João Pessoa: Universitária.

Pinton, F. A., Boskovitz, E. P., \& Cabrera, E. M. S. (2002). Uso de drogas entre os estudantes de medicina da Faculdade de Medicina de São José do Rio Preto, SP, no ano de 2002. Arquivos de Ciências da Saúde, 12 (2), 91-96.

Soares-Weiser, K., Weiser, M., \& Davidson, M. (2003). Uso de maconha na adolescência e risco de esquizofrenia. Revista Brasileira de Psiquiatria, 25 (3), 131-132.

Soldera, M., Dalgalarrondo, P., \& Correa Filho, H. R. (2004). Uso de drogas psicotrópicas por estudantes: prevalência e fatores sociais associados. Revista de Saúde Pública, 38 (2), 277-283.

Uchoa P. R.Y. M. (2003). Sistema nacional antidrogas. Revista de Cultura-IMAE, 4 (9), 22-29.

Recebido em: 29/8/2006

Versão final reapresentada em: 21/3/2007

Aprovado em: 23/4/2007 
